\title{
Improvement and stabilization of the electrochemical properties of zinc alloys during casting
}

\author{
V.A. Kechin, ${ }^{1 *}$ E.Y. Lyublinski, ${ }^{2 *}$ A.V.Kireev ${ }^{1}$ and E.S. Prusov ${ }^{1}$ \\ ${ }^{1}$ Vladimir State University, ul. Gor'kogo, 87, Vladimir, 600000, Russian Federation \\ ${ }^{2}$ COR/SCI, LLC, 6421 Dorset Lane, Solon, OH 44139, USA \\ *E-mail: kechin@vlsu.ru, elyublinski@gmail.com
}

\begin{abstract}
The main reasons for the appearance of electrochemical heterogeneity of cast sacrificial galvanic anodic alloys in the "metal-electrolyte" system are internal factors related to the nature of the metal, its composition, structure, etc. Obviously, when developing the technology for manufacturing of cast anodes, special attention should be paid to ensuring the structural homogeneity of the alloys. The main role in the formation of the structure and basic properties of cast anodes is played by thermal processes that affect the conditions for solidification of the melt in the mould. The results of studies of the structure and basic electrochemical properties of cast zinc sacrificial alloys (ZSA) depending on the cooling conditions are presented in this paper. The analysis of the temperature fields of the solidifying metal (when the metal is cooled) and the shape (when the mould is heated) at different cooling intensities has made it possible to optimize the duration of the casting cycle. This takes into account the cooling conditions determined by the initial temperature of the mould, which ensures a homogeneous structure and stable electrochemical properties of the material over the entire thickness of the tread. For example, it is established that for the casting of zinc alloys treads weighing $18 \mathrm{~kg}$, the temperature of the mould before casting should be $120-160^{\circ} \mathrm{C}$. In these conditions, the necessary quality of cast sacrificial anodic alloys is achieved: Current Capacity-Efficiency 93-96\%; Corrosion Potential $-E_{\mathrm{c}}=815-820 \mathrm{mV} v s$. SHE. The required duration of the casting cycle is 10-14 min. Similar data was obtained for sacrificial anodes of various shapes and sizes. Based on the results of studies of the thermal interaction of zinc anodes with a casting mould (sandy-argillaceous, cast iron and steel water-cooled) using numerical simulation methods, the expediency of casting anodes into water-cooled moulds is provided, providing the most favorable conditions for heat removal and obtaining a homogeneous structure of cast treads. Based on the results obtained, a technology has been developed for casting zinc anodes of various sizes, which provides high and stable electrochemical properties.
\end{abstract}

Key words: sacrificial anodes, structure, foundry, electrochemistry.

Received: October 12, 2018. Published: January 28, 2019

doi: $\underline{10.17675 / 2305-6894-2019-8-1-7}$ 


\section{Introduction}

The thermal processes play a leading role in the formation of most properties of castings during solidification of the melt [1-11]. Therefore, studying the conditions for solidification of the melt in a mould is the most important task of the thermal theory of casting. The urgency of this issue is also dictated by the fact that when casting the sacrificial anodes (SA), there are significant temperature fluctuations of metallic moulds [12]. Thus, continuous monitoring of temperature on one of the series cast iron moulds during the casting of zinc SA [following composition ZSA: Zn+(0.4-0.6\%) Al, contaminants less than: $\mathrm{Fe}-0.0015 \%, \mathrm{Cu}-0.001 \%, \mathrm{~Pb}-0.005 \%]$ noted that the initial temperature of the mould changes from 80 to $260^{\circ} \mathrm{C}$ during a shift (Figure 1). Apparently, this can explain the destabilization and reduction of the ZSA electrochemical properties that occur in the early stages of the use of SA, as well as contradictory data on the effectiveness of individual SA from one grade of alloy and even one melting [13].

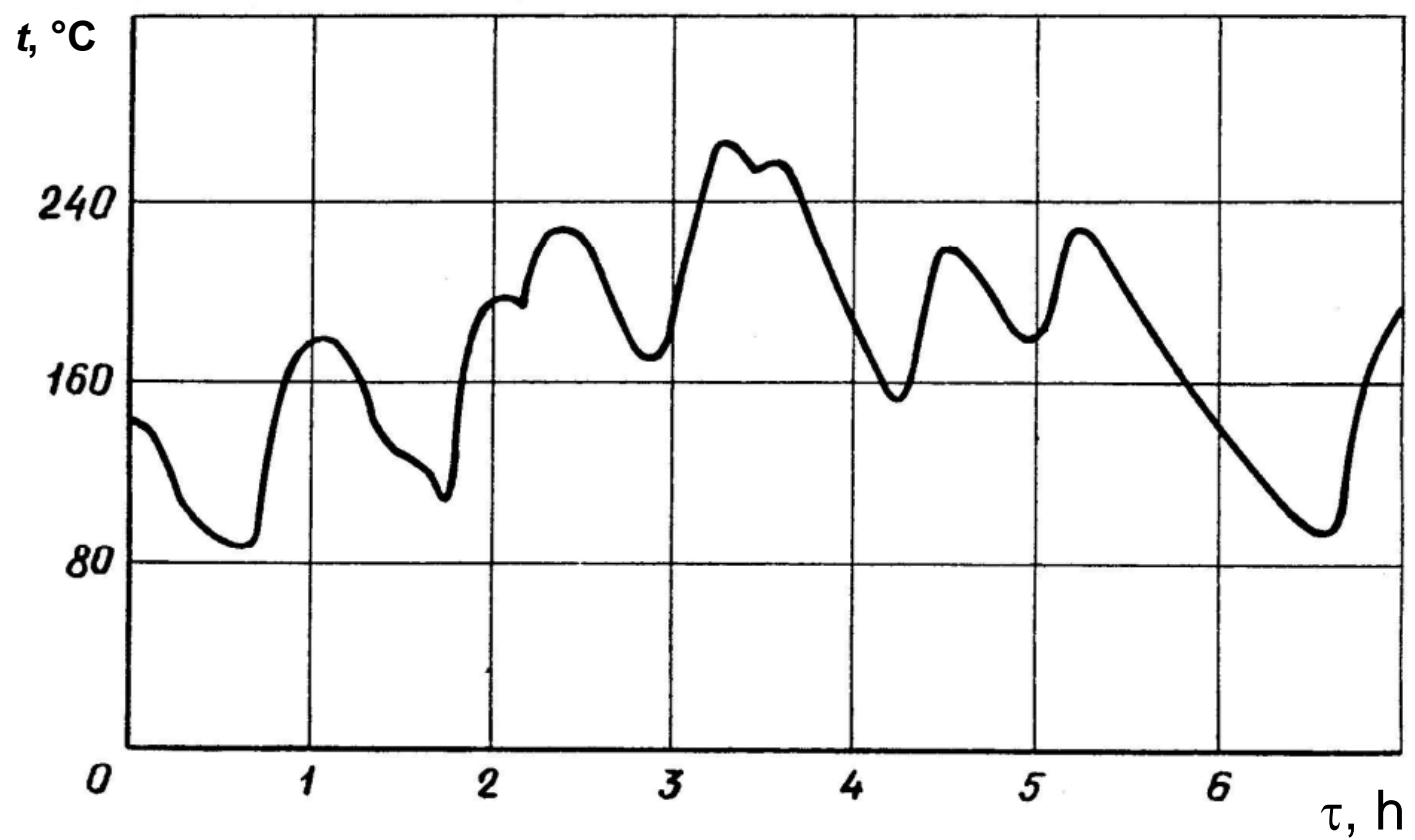

Figure 1. Change in mould temperature during the cast of ZSA.

When the temperature of the mould changes from 20 to $300^{\circ} \mathrm{C}$, the current capacity (CC) of zinc-aluminum alloy drops from 96 to $80 \%$. Obviously, the lack of control over the temperature of the moulds before casting the alloy leads to a dispersion of the protective properties and, especially, of the CC. When considering the macrostructure of the ZSA, filled in metal moulds with different initial temperatures, three characteristic zones are distinguished: cortical, columnar and non-oriented crystals (Figure 2). The most uniform fine-grained structure is obtained in the moulds with an initial temperature of $20^{\circ} \mathrm{C}$ (a) and $160^{\circ} \mathrm{C}$ (b). When casting the alloy in a mould with an initial temperature of $310^{\circ} \mathrm{C}$ (c), zoning is clearly indicated in the crystalline structure of the tread. Obviously, 
the above CC spread is determined primarily by the crystal structure of the protectors, which depends, in the main, on the nature of the solidification of the metal.

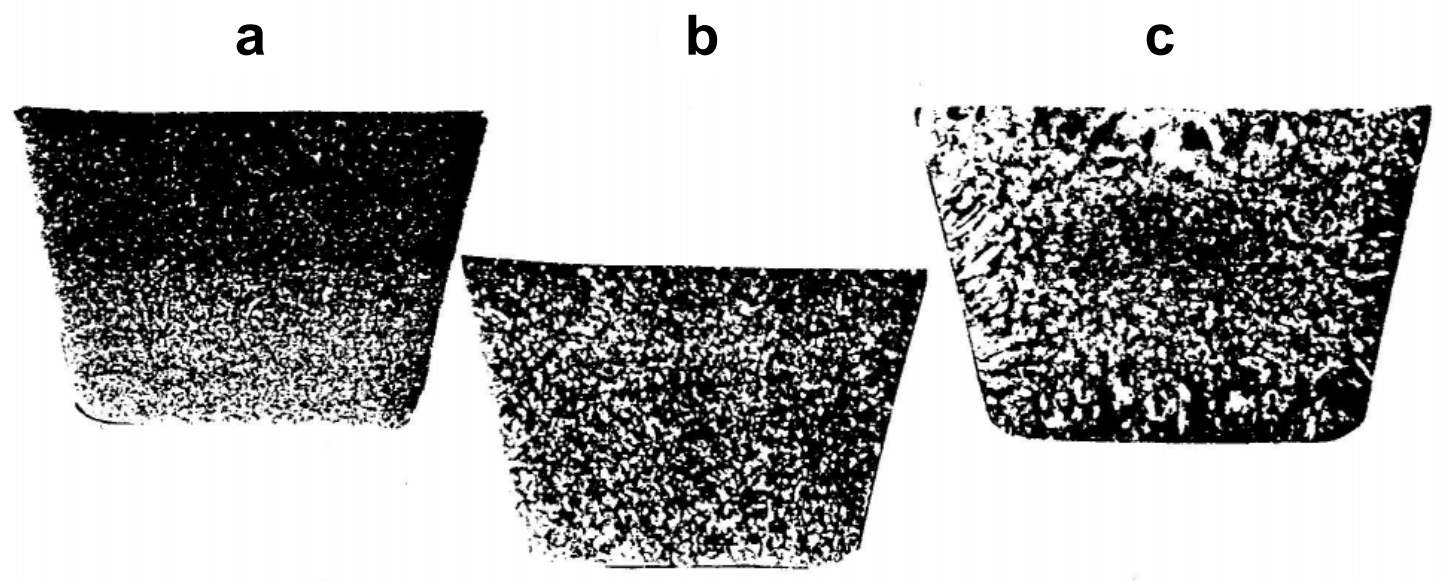

Figure 2. Macrostructure of zinc sacrificial anodes under various conditions of solidification and cooling in the mould at initial temperature of the mould $20^{\circ} \mathrm{C} \mathrm{(a),} 160^{\circ} \mathrm{C}$ (b) and $310^{\circ} \mathrm{C}$ (c).

The main purpose of this work is to study the structure and basic electrochemical properties of cast sacrificial anodes from $\mathrm{Zn}-\mathrm{Al}$ alloys depending on the thermal conditions of cooling.

\section{Materials and Methods}

The object of the research was the tread alloy of the $\mathrm{Zn}-\mathrm{Al}$ system (Table 1).

Table 1. Chemical composition of the ZSA alloy, mass\%.

\begin{tabular}{ccccc}
\hline $\mathbf{Z n}$ & Al & Fe & Pb & Cu \\
\hline Main & 0.53 & 0.013 & 0.005 & 0.001 \\
\hline
\end{tabular}

The temperature of casting in all experiments was kept constant $\left(480^{\circ} \mathrm{C}\right)$. The initial temperature of the cast iron mould was 20,160 and $310^{\circ} \mathrm{C}$. The solidification of cast treads was studied by the methods of thermometry and pouring out. The temperature fields of the tread and the shapes constructed from the cooling curves of the melt solidification in the mould and curves characterizing the change in temperature in the mould were investigated by thermometry. The thermocouple arrangement for removing the temperature fields in the cast tread and the shape is shown in Figure 3. Data was recorded using an automatic twelve-point potentiometer. 


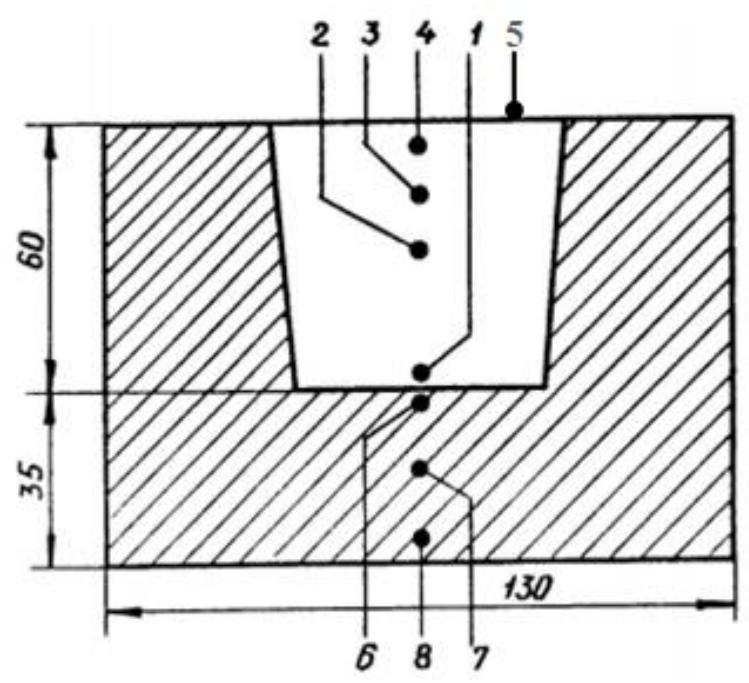

Figure 3. The scheme of installation of thermocouples for measuring the temperature fields of a hardening alloy (1-5) and cast-iron moulds (6-8).

To study the basic electrochemical properties of the alloys (stationary and operating potential, current output, and CC), electrochemical tests of samples with a diameter of 15 and a height of $17 \mathrm{~mm}$ were performed in $3 \%$ aqueous solution of $\mathrm{NaCl}$ with anodic polarization with a current of $3 \mathrm{~mA} / \mathrm{m}^{2}$. The values of the potentials were fixed using the potentiator model IPC and the silver chloride reference electrode. The data was converted to the hydrogen reference electrode. For the test, the samples were prepared as follows: washed in hot water; rubbed with alcohol for degreasing; poisoned in 5\% hydrochloric acid for 5-10 seconds; washed in hot and then in cold water; dried and kept in a desiccator over freshly prepared $\mathrm{CaCl}_{2}$ for a day and weighed. The samples prepared in this way were screwed onto copper holders protected from water by a PVC tube. To prevent electrolyte contact with the holder, the end of the tube at the sample and the end of the sample were coated with a mixture of bitumen (2/3) and paraffin (Figure 4).

\section{Results and Discussion}

Figure 5, I presents the results of the solidification study of the ZSA in a mould whose initial temperature was $20^{\circ} \mathrm{C}$. An analysis of the temperature fields in the cast tread and the shape, constructed from the curves characterizing the change in temperature in the solidifying metal and in the mould, gives an idea of the nature of the solidification and the state of the mould during the cooling period. Heat removal from the hardening metal occurs due to the accumulation of heat by a metal mould, the temperature of which rises from 20 to $180^{\circ} \mathrm{C}$, and also some heat radiation through the open gate part of the tread. Increased temperature in the center of the casting (thermocouple 3) in comparison with other zones is explained by the greatest remoteness of this zone from heat-removing surfaces. Similar data were obtained during solidification of the ZSA in moulds with an initial temperature of $160^{\circ} \mathrm{C}$ (Figure 5, II) and $310^{\circ} \mathrm{C}$ (Figure 5, III). 


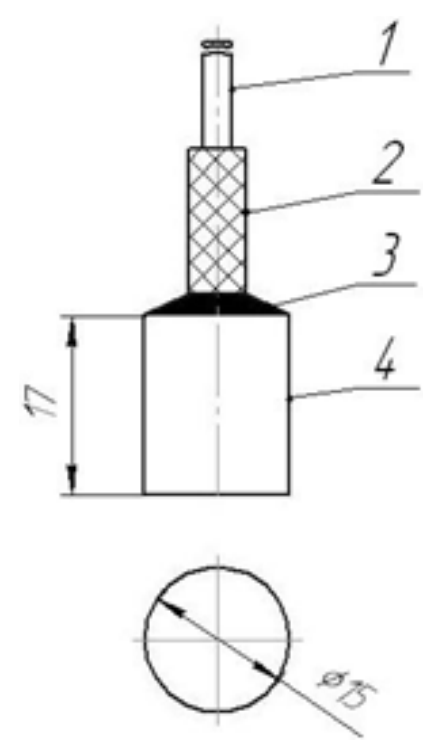

Figure 4. A sample for electrochemical testing, fixed on a holder and coated with a mixture of bitumen and paraffin: 1 - copper holder, 2 - PVC pipe, 3 - coating, 4 - test sample.

Moreover, if the alloy is solidified in a mould at a temperature of $160^{\circ} \mathrm{C}$, heat removal from the cast protector is due to the accumulation of heat by a mould whose temperature increased from 160 to $240^{\circ} \mathrm{C}$, as well as some heat radiation through the open gate surface, when the alloy solidifies with a temperature of $310^{\circ} \mathrm{C}$, heat removal is carried out mainly due to thermal conductivity (the temperature of the mould is practically unchanged and is $310-330^{\circ} \mathrm{C}$ ) and partly the heat radiation through the open gate surface of the tread. A different heat sink from the casting leads to a different temperature drop across the cross section of the cast tread, thereby changing the nature of the solidification. The best conditions for directional solidification are provided at a higher temperature drop (solidification of the alloy in a mould with a temperature of up to $160^{\circ} \mathrm{C}$ ).

To determine the nature of solidification by the method of pouring, the alloy cast into the mould was poured out at regular intervals by tipping the mould. After leakage of liquid and solid-liquid residues, a solid shell-cake remained in the mould. The hardness of the alloy as a function of the initial mould temperature (Figure 5) was evaluated for thickness $\delta_{\mathrm{k}}(\mathrm{mm})$ and mass $m_{\mathrm{k}}(\mathrm{kg})$ for the thickness of solid casting crusts.

The data on the thickness and mass change of the casting crust at certain intervals (Table 2) indicate a significant effect of the heat removal intensity on the character and rate of solidification of the ZSA. The time of complete solidification of the ZSA tread in metallic mould with an initial temperature of 20,160 and $310^{\circ} \mathrm{C}$ is different and is respectively; 215,255 and $440^{\circ} \mathrm{C}$. The appearance of the formed crusts in the process of solidification of the alloy in moulds with different initial temperatures in comparison with the data on the change in their thickness and mass at definite intervals of time confirmed the effect of heat removal conditions on the nature of solidification. Thus, different cooling conditions lead to a change in the temperature drop across the section of the cast sacrificial anodes, thereby changing its crystal structure and properties. 


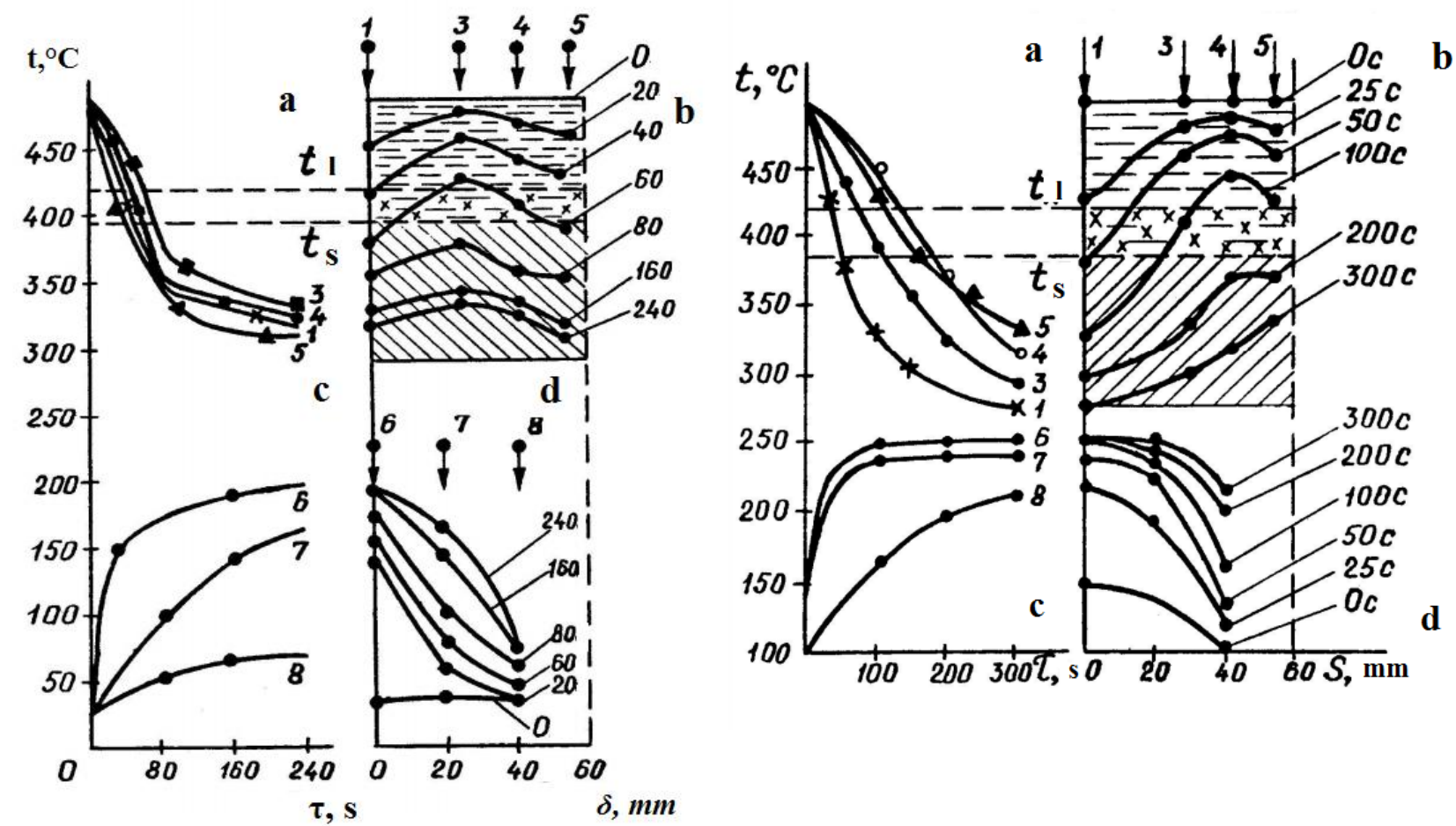

I

II

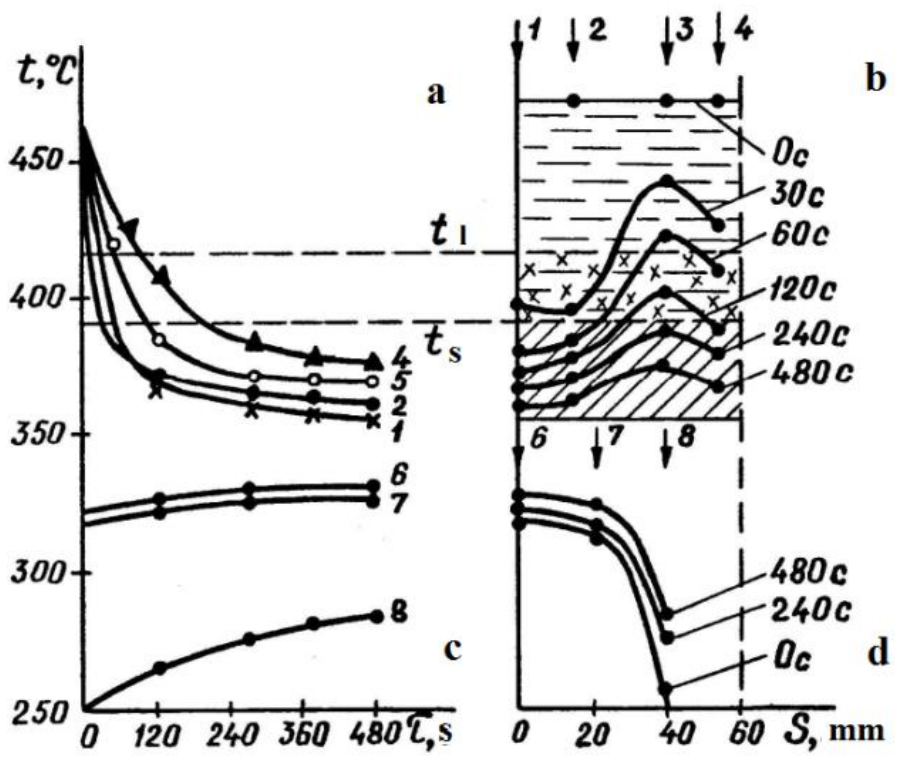

III

Figure 5. Temperature variation in the solidifying alloys and cast-iron mould at their height at a mould temperature of $20^{\circ} \mathrm{C}$ (I), $160^{\circ} \mathrm{C}$ (II), $310^{\circ} \mathrm{C}$ (III): a, b - cooling and heating curves, respectively; $\mathrm{c}, \mathrm{d}$ - the temperature fields in the solidifying alloy and the shape, respectively. 
Table 2. Data on solidification of cast treads made of ZSA under various conditions and duration of cooling.

\begin{tabular}{|c|c|c|c|c|c|c|}
\hline \multirow{3}{*}{$\begin{array}{c}\text { Cooling } \\
\text { duration, } \mathrm{s}\end{array}$} & \multicolumn{6}{|c|}{ Initial temperature of mould, ${ }^{\circ} \mathrm{C}$} \\
\hline & \multicolumn{2}{|c|}{20} & \multicolumn{2}{|c|}{160} & \multicolumn{2}{|c|}{310} \\
\hline & $m_{\mathrm{k}}, \mathrm{kg}$ & $\delta, \mathbf{m m}$ & $m_{\mathrm{k}}, \mathrm{kg}$ & $\boldsymbol{\delta}, \mathbf{m m}$ & $m_{\mathrm{k}}, \mathrm{kg}$ & $\delta, \mathbf{m m}$ \\
\hline 20 & 4.6 & 9 & 5.2 & 8 & 1.8 & 6 \\
\hline 40 & 6.9 & 13 & 6.4 & 13 & 3.4 & 6.5 \\
\hline 60 & 9.4 & 20 & 7.6 & 15 & 4.9 & 7 \\
\hline 100 & 11.2 & 25 & 11.8 & 20 & 7.6 & 14 \\
\hline 120 & 11.8 & 27 & 12.5 & 25 & 9.2 & 16 \\
\hline 140 & 13.0 & 32 & 14.0 & 27 & 9.7 & 18 \\
\hline 180 & 15.2 & 41 & 15.5 & 40 & 11.0 & 22 \\
\hline 215 & 16.0 & 60 & 16.1 & 46 & 12.3 & 25 \\
\hline 240 & - & - & 16.3 & 54 & 13.0 & 27 \\
\hline 255 & - & - & 16.4 & 60 & 13.3 & 28 \\
\hline 300 & - & - & - & - & 13.8 & 31 \\
\hline 360 & - & - & - & - & 14.8 & 37 \\
\hline 440 & - & - & - & - & 16.1 & 60 \\
\hline
\end{tabular}

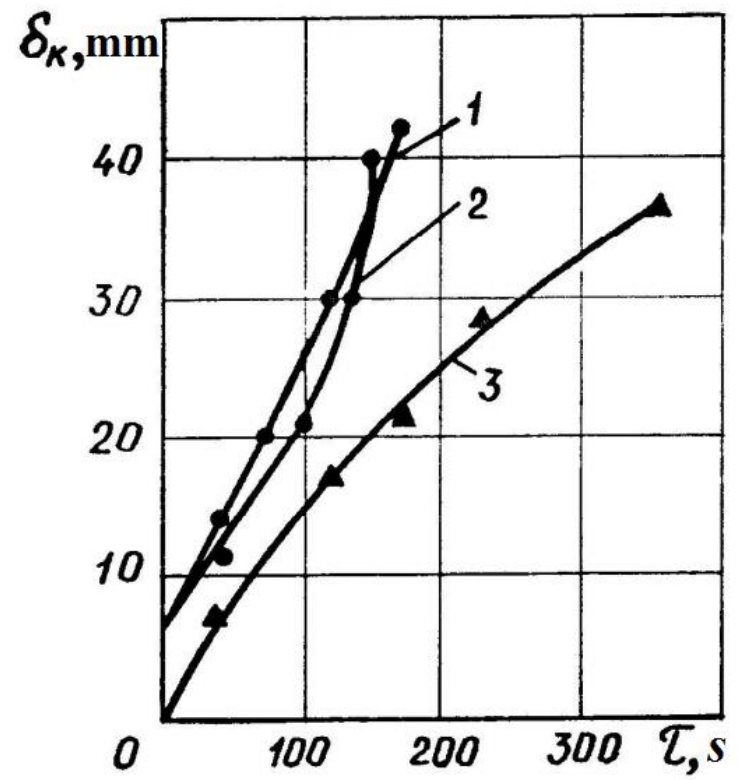

a

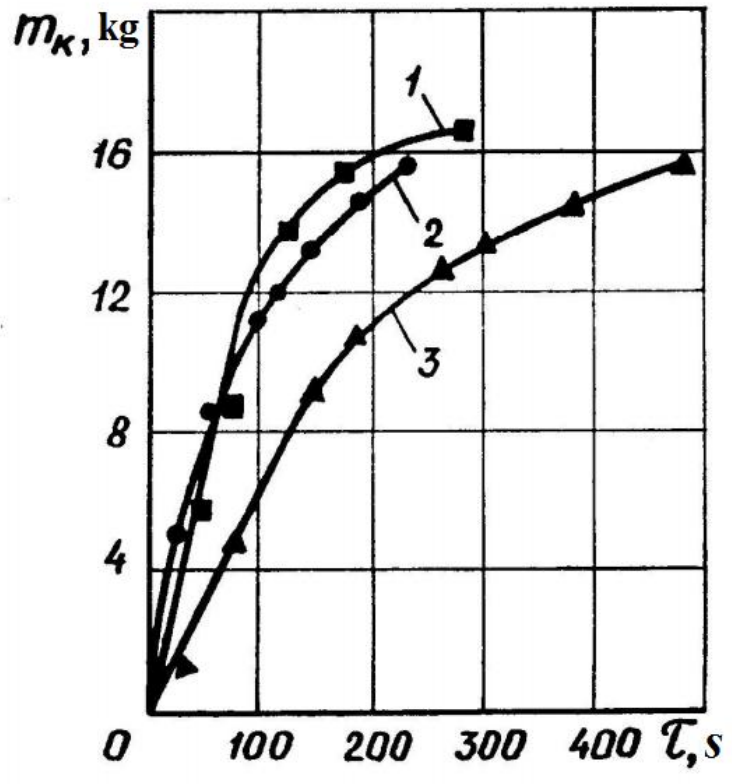

b

Figure 6. Change in thickness (a) and mass (b) of metal under different cooling conditions. $1,2,3$ - initial temperature of the mould, equal to 20,160 and $310^{\circ} \mathrm{C}$, respectively. 
Comparative evaluation of the main electrochemical properties of the anodes from the ZSA obtained at different initial temperatures of the mould (Table 3) shows that if the value of the stationary potential and the potential at polarization with a current density $3 \mathrm{~A} / \mathrm{m}^{2}$ does not depend on conditions and nature of solidification.

Table 3. The main tread properties of the CP1 alloy at various initial temperatures of the mould.

\begin{tabular}{cccc}
\hline \multirow{2}{*}{ Temperature, ${ }^{\circ} \mathbf{C}$} & \multicolumn{2}{c}{ Potential, $\boldsymbol{~} \boldsymbol{E}(\mathbf{m V})$} & \multirow{2}{*}{ Capacity, \% } \\
\cline { 2 - 3 } & Stationary & By polarization & \\
\hline 20 & 820 & 690 & $92-96$ \\
160 & 815 & 690 & $90-93$ \\
310 & 820 & 680 & $80-87$ \\
\hline
\end{tabular}

The capacity varies from $80-85 \%$ to $91-95 \%$. Since the metal mould is used to cast treads many times during the shift, an important task of controlling the casting process to produce cast treads with a stable homogeneous structure and properties is to maintain the mould temperature at the same level before the next pouring.

In the steady-state casting process, the initial mould temperature must be constant for a given duration of the casting cycle $\left(t_{\mathrm{c}}\right)$, which is composed of the duration of solidification and cooling of the anodes in the mould $\left(t_{1}\right)$ and cooling the mould to the specified initial temperature $\left(t_{2}\right)$.

The change in the duration of solidification and cooling of the tread in the metallic mould $\left(t_{1}\right)$ and the duration of its cooling to the set temperature $\left(t_{2}\right)$ depends on the accepted initial temperature of the mould.

It can be seen (Figure 6) that for different given mould temperatures, the time of the casting cycle is the same. Therefore, in order to choose the cycle duration, one must take into account the cooling conditions determined by the initial temperature of the mould, at which uniformity of the structure and stable properties of the alloy are ensured. For zinc tread casting, the temperature of the mould before casting should be $120-160^{\circ} \mathrm{C}$. Under these conditions, a good quality of the treads is achieved with a casting time of 10 to 14 minutes.

Below, we consider the structure and properties of zinc alloys ZSA1 and ZSA2 depending on the casting temperature and cooling conditions. Samples for research were poured at 450 and $500^{\circ} \mathrm{C}$ into cast iron and chamotte moulds. To determine the comparative data revealing the role of technological factors in the anodic process of dissolution of sacrificial alloys, their main properties were determined: stationary potential $\left(-\varphi_{c}\right)$, potential at polarization $\left(-\varphi_{p}\right)$ and current capacity. Samples were tested in artificial seawater for 10 days. The results of the experiments show that the protective properties of alloys depend on the temperature conditions of the casting and the material of the mould. Thus, with an increase in the casting temperature from 450 to $550^{\circ} \mathrm{C}$ (Figure 8), when 
casting samples in a nonmetallic (chamotte) mould, the CC decreases for the ZSA1 alloy from 93 to 85\%; for alloy ZSA2 - from 94 to 86\%. These alloys, cast in a metallic (castiron) form with $450 ; 500$ to $550^{\circ} \mathrm{C}$ change the CC for alloy ZSA1 from 94 to $89 \%$; for alloy ZSA2 - from 94 to $91 \%$. The stationary potentials $\left(E_{\mathrm{s}}\right)$ and potentials at polarization $\left(E_{\mathrm{p}}\right)$ of alloys with increasing the casting temperature changing slightly. So, for alloys of ZSA1 and ZSA2 the $-E_{\mathrm{s}}$ changed within $800-830 \mathrm{mV} ;-E_{\mathrm{p}}$ has slightly lower values (730-760 mV).

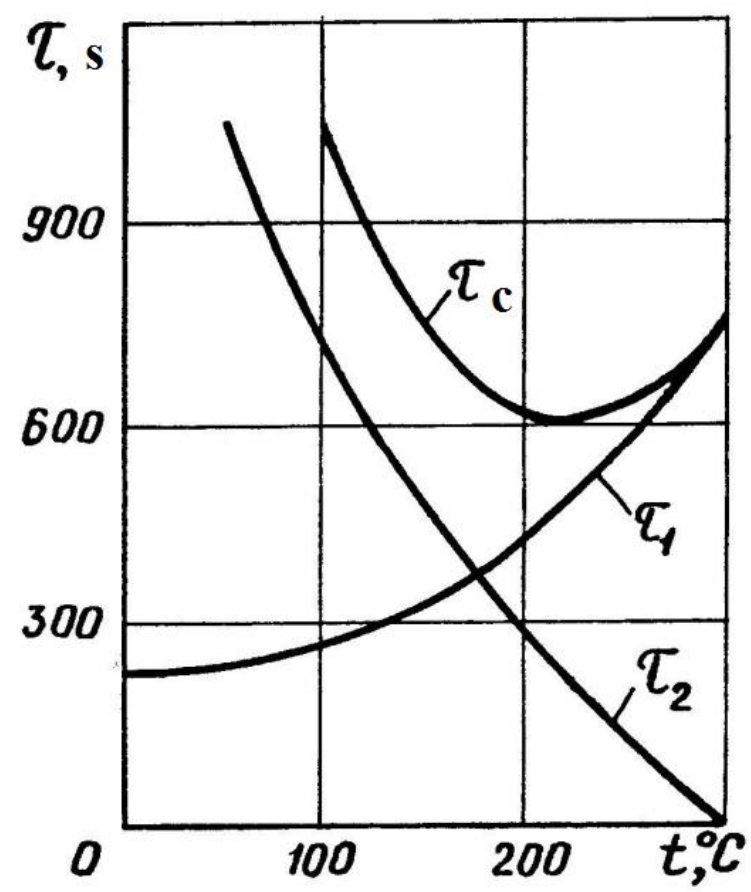

Figure 7. Dependence of the cooling time of the casting in the mould $t_{1}$, cooling the mould to the set temperature $t_{2}$ and the total casting cycle $t_{\mathrm{c}}$ from the initial temperature of the mould.
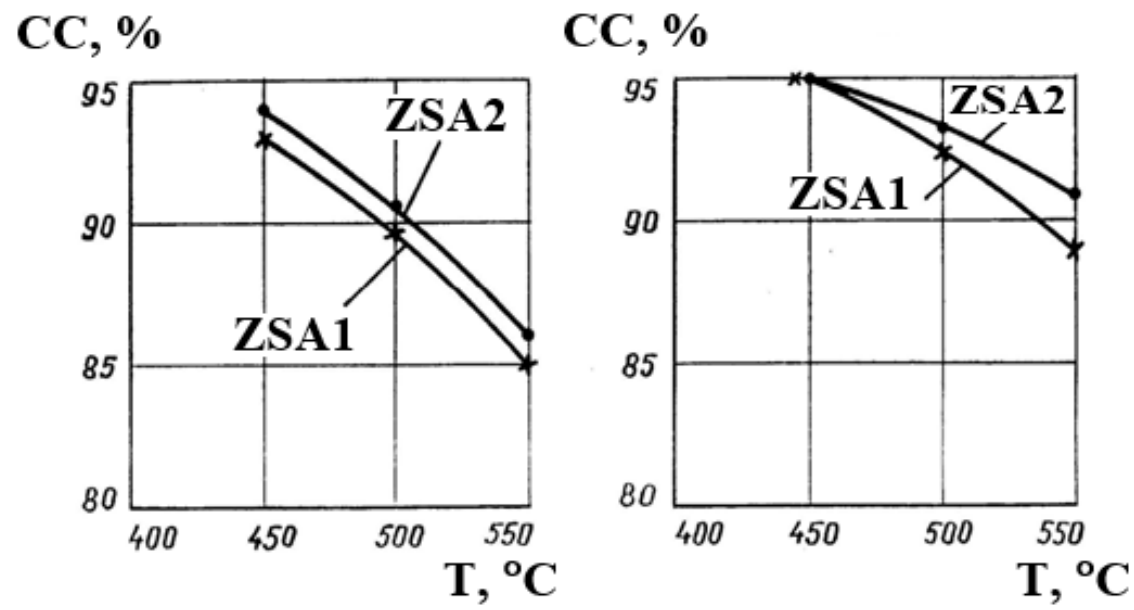

Figure 8. Influence of the casting temperature on the change of zinc alloys CC by casting into nonmetallic (a) and metallic moulds (b). 
The material of the mould also exerts a significant influence on the $\mathrm{CC}$ of alloys (intensity of cooling). Thus, for unambiguous casting temperatures $\mathrm{CC}$ for casting into a metal mould for alloys, ZSA1 and ZSA2 is of somewhat greater importance, especially when casting samples with 500 and $550^{\circ} \mathrm{C}$. A comparative analysis of the data on the change in the $\mathrm{CC}$ of the alloys with their microstructure (Figure 9) obtained at different casting temperatures shows that an increase in temperature leads to a coarsening of the microstructure with an increase in the dimensions of the second phase, as a result of which a decrease in the $\mathrm{CC}$ is observed. When casting alloy ZSA2 in a metal mould, the casting has a fine-grained structure.

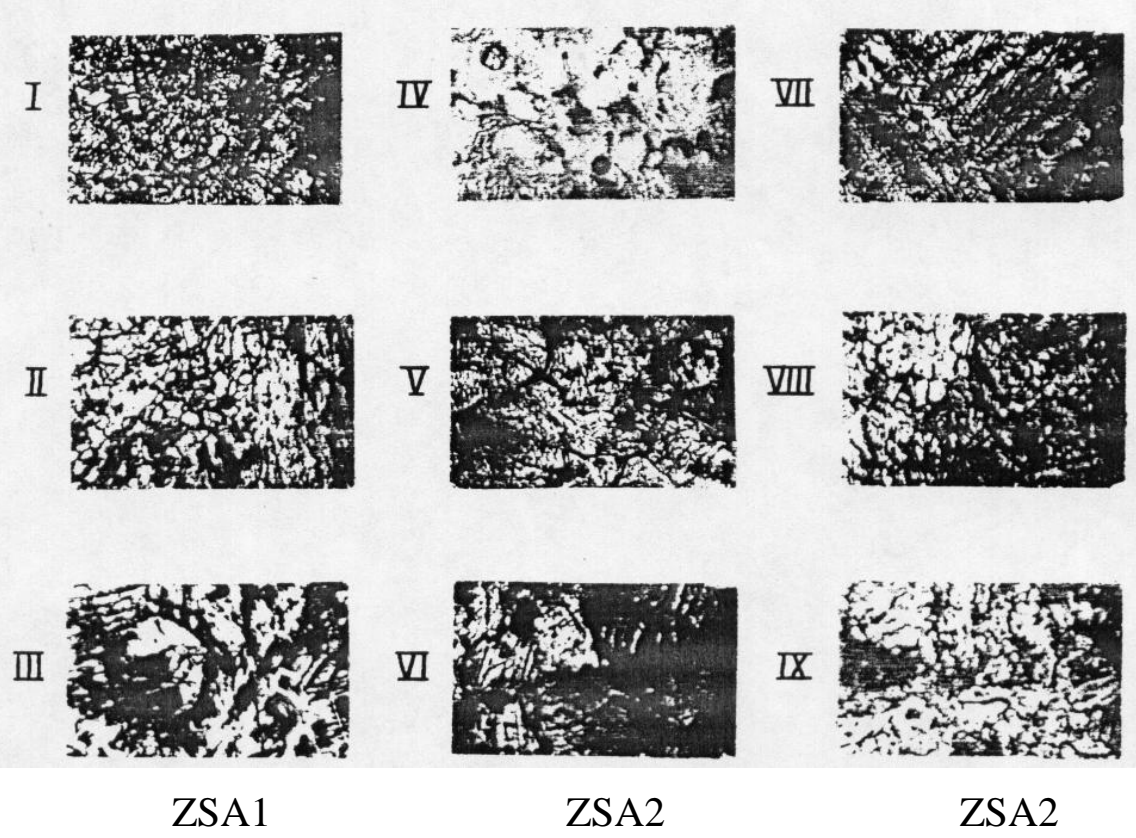

Figure 9. Microstructure of the alloys of CP1 (I, II, III), CP2 (IV, V, VI) when casting into nonmetallic and metallic (VII, VIII, IX) moulds at the following casting temperatures: I, IV, VII $-450^{\circ} \mathrm{C}$; II, V, VII $-500^{\circ} \mathrm{C}$; III, VI, IX $-550^{\circ} \mathrm{C}(\times 100)$.

Comparison of these structures with $\mathrm{CC}$ of alloy ZSA2 shows that, due to insignificant changes in the nature of the microstructure, the $\mathrm{CC}$ falls by only $3-5 \%$. When casting into a metal mould, the $\mathrm{CC}$ is always higher than when casting into a nonmetallic shape. The difference in the value of $\mathrm{CC}$ increases with an increased casting temperature (500 and especially $550^{\circ} \mathrm{C}$ ). Obviously, the higher and stable protective properties of the alloys are achieved by grinding the structure, due to a more even distribution of structural components, which reduces the rate of self-dissolution of solid solutions by reducing and leveling local micro-pairs. As a result of mathematical processing of the dependence of the $\mathrm{CC}$ of the ZSA1 alloy on the casting temperature $\left(t_{\mathrm{c}}\right): 450 ; 500 ; 550^{\circ} \mathrm{C}$ at $V_{\mathrm{s}}=$ const $=$ $150^{\circ} \mathrm{C} / \mathrm{min}$, the following regression equation was obtained:

$$
\mathrm{CC}=127-0.072 t_{\mathrm{c}}
$$


The equation is adequate for the given casting temperatures, since the following condition is met for a linear model: $\tau_{\mathrm{c}}^{\text {calc }}>\tau_{\mathrm{c}}^{\text {crit }}\left(\tau^{\text {calc }}=0.998 ; \tau^{\text {crit }}=0.878\right.$ for $\left.\alpha=0.05\right)$.

On the example, the change in the principal protective properties as a function of the solidification rate $\left(V_{\mathrm{S}}\right)$ at a constant casting temperature of $450^{\circ} \mathrm{C}$ has been studied. To study the influence of the rate of solidification on the properties of alloys, the samples were cast into cast iron and chamotte moulds with an initial temperature of 20 and $180^{\circ} \mathrm{C}$. The rate of solidification of alloys was changed within the limits of limits of 20 to $284 \mathrm{deg} / \mathrm{min}$. In all experiments, regardless of the rate of solidification, the stationary potentials $\left(\varphi_{\mathrm{s}}\right)$ and potentials at polarization $\left(\varphi_{\mathrm{p}}\right)$ change insignificantly. Thus, for alloys of ZSA1 and ZSA2 the $-\varphi_{\mathrm{s}}$ varies from 800 to $830 \mathrm{mV}$; and $-\varphi_{\mathrm{p}}$ in the range $730-760 \mathrm{mV}$. The $\mathrm{CC}$ values of the alloys increase with the rate of solidification (Figure 10). The dependence of the CC of the ZSA1 alloy on the rate of cooling upon solidification $\left(V_{\mathrm{s}}: 25,105,230,280 \mathrm{deg} / \mathrm{min}\right)$ is expressed by the following regression equation:

$$
\mathrm{CC}=84.21+0.035 V_{\mathrm{s}} \text {. }
$$

The equation is adequate for the given solidification rates, since the following condition is met for a linear model: $\tau_{\alpha}^{\text {calc }}>\tau_{\alpha}^{\text {crit }}\left(\tau^{\text {calc }}=0.9993 ; \tau^{\text {crit }}=0.95\right.$ for $\left.\alpha=0.05\right)$.

Moreover, for alloys ZSA1 and ZSA2 at a solidification rate of $20-25 \mathrm{deg} / \mathrm{min}$, the spread of the CC values will be much larger than at the solidification rate of 220-280 $\mathrm{deg} / \mathrm{min}$. The data on the change in the $\mathrm{CC}$ and the microstructure of the alloys ZSA1 and ZSA2, depending on the rate of solidification, are in good agreement with the conclusions drawn above.
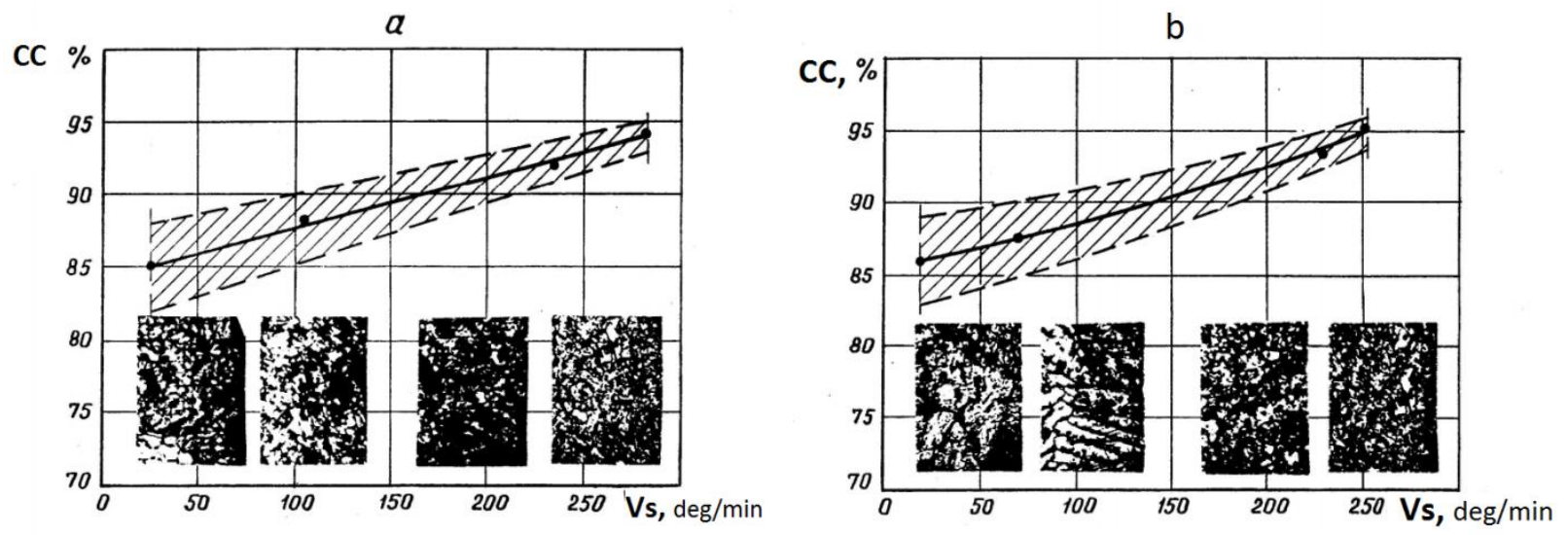

Figure 10. Change in CC and microstructure of ZSA1 (a) and ZSA2 (b) alloys, depending on the rate of solidification.

During the development and application of the technology of manufacturing ZSA of various sizes, shaking open cast iron moulds were used. This dramatically reduced the complexity of casting as compared to casting in split vertical chill moulds, significantly improved quality and eliminated recyclable waste. 
Taking into account the role of thermal processes to ensure the directional solidification of the ingots, studies were carried out to improve the design of the mould (Figure 11) to obtain sacrificial cast zinc anodes [14]. The side walls of the mould 1 are made thin-walled with a casing 2 ; between the walls and the casing is a heat-insulating gap 3 . The base of the mould is provided with a water-cooled pallet 5. A heat-shielding screen is installed on the upper part of the mould with the help of support plates 6 . The mould is used for casting in the following way. Prior to pouring the metal, a heat-insulating screen 7 is removed which rests on the side walls of the casing 2 with support plates 6 . Cooling water is passed through the tray to cool the base 4 during the entire operation cycle.
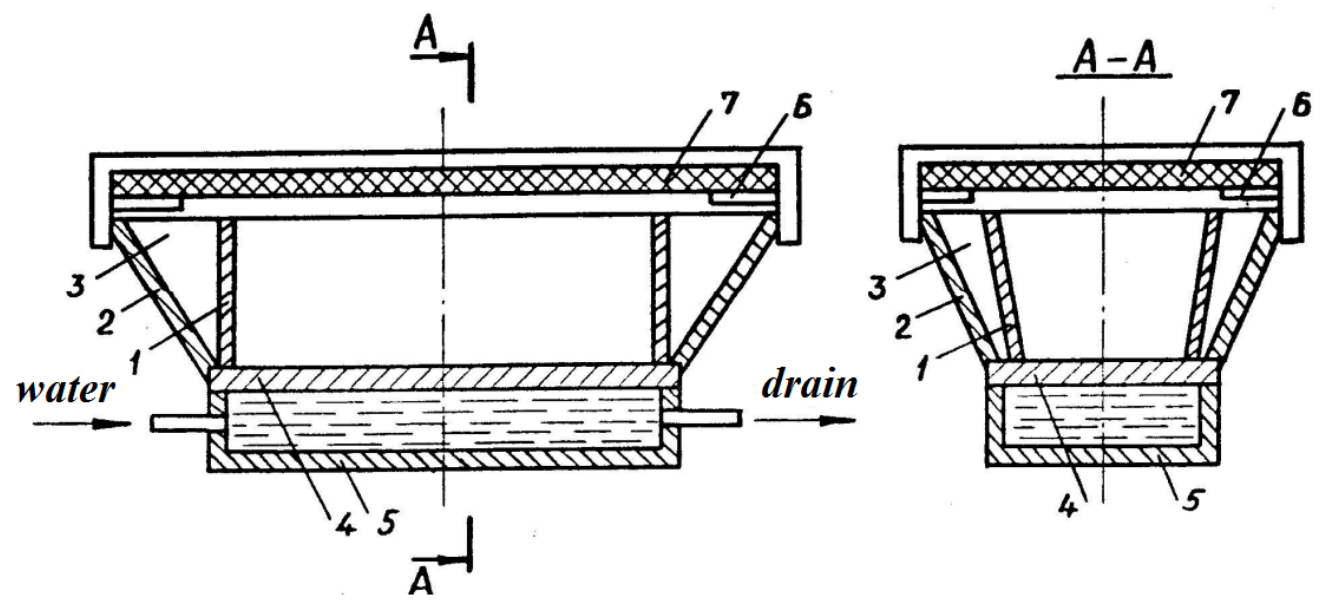

Figure 11. Construction of a mould for the production of zinc treads (sacrificial anodes).

The organization of the controlled and directed heat sink (from the bottom to the top) by means of water cooling of the lower part of the mould, the creation of a heat-insulating gap on its side walls and the elimination of heat losses from the upper casting part of the casting by applying a heat-insulating shield allow providing the best conditions for directional solidification of the metal and obtaining a homogeneous crystalline structure of castings.

Due to the fact that the adjustable heat sink provides a directional advance of the crystallization front, conditions are created for obtaining an even casting surface of the casting. With the help of the lateral wall, varying in height, the form of the gap retains a predetermined rate of crystallization throughout the entire section of the casting.

The heat-insulating gap can be filled with air, asbestos or other heat-insulating material. The evaluation of the quality of zinc anodes made of alloy ZSA1 cast in the form of an improved design showed that water cooling only the lower part of the mould (with the elimination of heat losses from the upper part of the mould (with the exclusion of heat losses from the upper part of the casting) in combination with the thermal insulation of the side walls of the mould by means of a gap it is possible to obtain ZSA with a high degree of homogeneity of the crystal structure and a smooth surface without shrinkage holes. CC of cast zinc anodes reaches $96-98 \%$, and the stock utilization rate is $100 \%$, since it 
eliminates the need for machining the upper sprue part of the tread. The duration of the cycle when casting into water-cooled moulds is reduced in comparison with casting into cast iron (a full casting cycle when the tread is cast into the water-cooled mould is $2-3$ min (Figure 12), and in cast iron - 10-14 min. Evidently, the transition to the casting of ZSA in water-cooled moulds will provide high technical and economic indicators both in production and using cast treads.

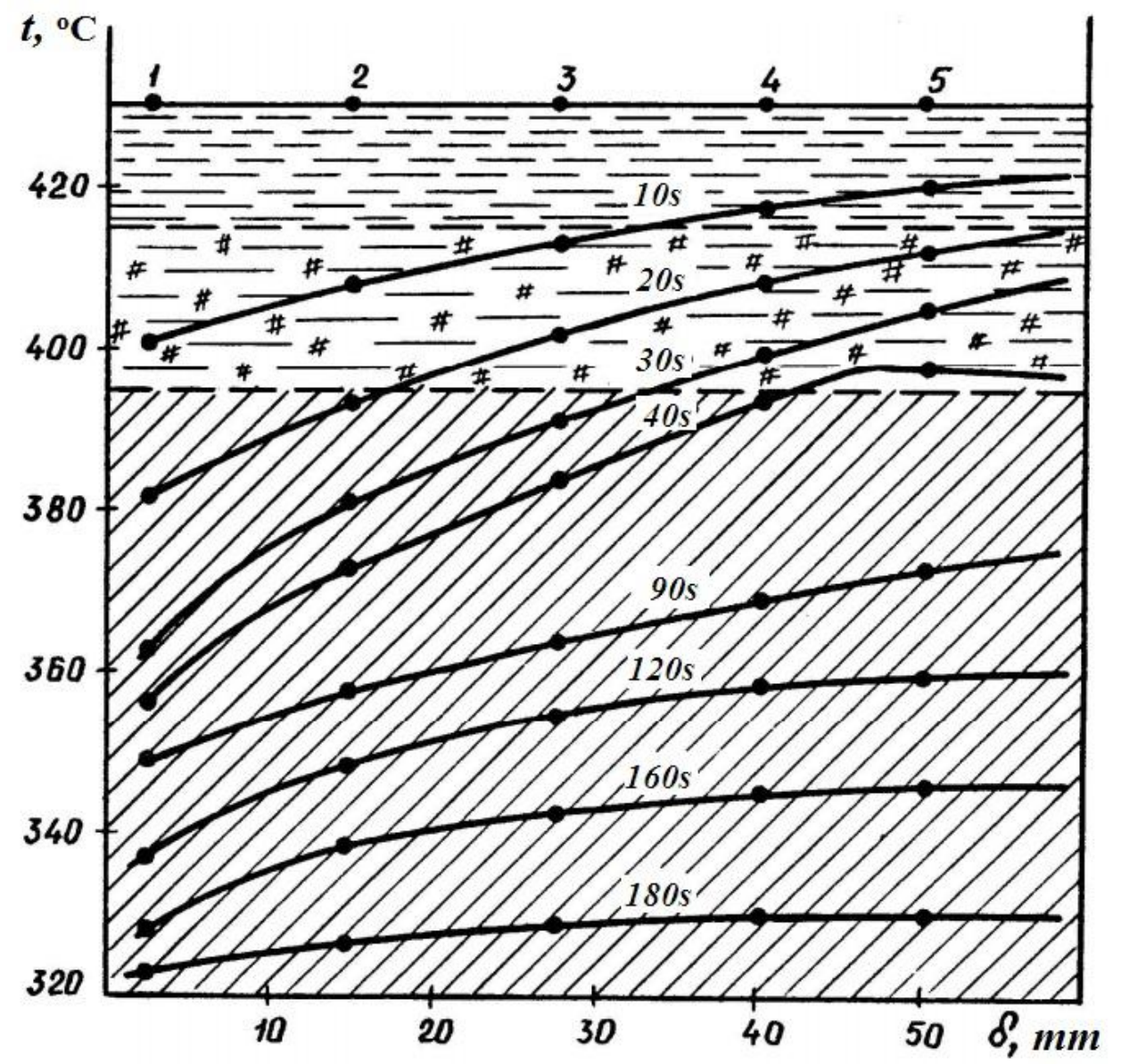

Figure 12. Changing the temperature of the cast tread when casting into a water-cooled mould.

The study of the thermal interaction of ZSA with a shape using numerical simulation methods confirmed the conclusions drawn from the results of experiments on the advisability of casting sacrificial anodes into water-cooled forms that provide the most favorable heat removal conditions and obtaining a uniform structure of the cast metal. 


\section{Conclusions}

1. It is shown that different cooling conditions lead to a change in the temperature drop across the section of the cast zinc sacrificial anodes, changing their electrochemical properties.

2. The best conditions for directional solidification of the ingot are ensured at a higher temperature difference (solidification of the alloy in a mould with a temperature not higher than $160^{\circ} \mathrm{C}$ ).

3. Investigation of the thermal conditions of solidification of zinc ingots showed that the minimum time for a complete casting cycle, including filling and cooling of the zinc ingot, in the absence of forced cooling is achieved at the initial temperature of the metallic mould of $180-200^{\circ} \mathrm{C}$.

4. Since metal moulds are used to produce ingots many times during the shift, the important task of controlling the casting process is to maintain their temperature before the next pouring at a constant level, including using forced cooling by casting into water-cooled shapes with a directed heat sink.

5. The present results allow to achieve the highest current capacity and stable potential at anodic polarizations.

\section{References}

1. D.M. Stefanescu, Science and Engineering of Casting Solidification, 3rd ed., 2015, Springer International Publishing AG, Switzerland, p. 559.

2. J. Dantzig and M. Rappaz, Solidification, 2009, Taylor \& Francis Group, CRS Press, p. 621.

3. J. Campbell, Casting, 2nd ed., 2003, Butterworth-Heinemann, Elsevier, p. 335.

4. F.S. Yang and F. Ni, Effect of Cooling Rate on the Solidification of Zn-5wt\%Al Alloy, Adv. Mater. Res., 2012, 366, 502-505.

5. M. Krupiński, B. Krupińska, K. Labisz, Z. Rdzawski and W. Borek, Influence of cooling rate on crystallization kinetics on microstructure of cast zinc alloys, J. Therm. Anal. Calorim., 2014, 118, no. 2, 1361-1367.

6. R.-N. Ma, Y.-Z. Fan, A. Du and P.-P. Zhang, Effect of cooling rate on morphology and corrosion resistance of $\mathrm{Zn}-\mathrm{Al}-\mathrm{Mg}$ alloy, Cailiao Rechuli Xuebao/Transactions of Materials and Heat Treatment, 2015, 36, no. 4, 49-55.

7. V.A. Kechin and E.Y. Lyublinski, New Sacrificial Anodic Alloys, NACE International, 2018, Phoenix, USA, Paper C2018-11388.

8. C. Jennings, A comparison of the structure and Consumption Rate for Centrifugally Cast Anodes Compared with Die-Cast Anodes, NACE International, 2018, Phoenix, USA, Paper C2018-10954.

9. E. Lyublinski and V. Kechin, Formation of basic properties of galvanic anodes during the industrial production, EUROCORR 2017, Prague, Czhech Republic, Paper 72701. 
10. A. Aghajani, M. Atapour and R. Alibek, Passivation of Zinc Anodes in Marine Conditions, Mater. Perform., 2016, 55, no. 9, 34.

11. V. Kechin and E. Lyublinski, New Sacrificial Anodic Alloys, EUROCORR 2016, Montpellier, France, Paper 0-6242.

12. V.A. Kechin, Theory and Technology of Cast Sacrificial Materials, Vladimir State University, 2004, p. 181 (in Russian).

13. V.A. Kechin and E.Y. Lyublinski, Zinc Alloys, Moscow, Metallurgiya, 1986, p. 247 (in Russian).

14. V.A. Kechin and A.B.Kireev, Riser for the production of cast treads sacrificial anodes, RF Patent No. 2492020, 2013 (in Russian). 